\title{
ANALISIS PERFORMA EXTRACTION CONDENSING TURBINE UNIT 1 DI PLTU BABELAN
}

\author{
* Andrian Saputro ${ }^{1}$, Intan Soleha ${ }^{2}$ \\ ${ }^{1,2}$ Fakultas Teknik dan Informatika, Program Studi Teknik Mesin, Universitas Dian Nusantara, Jakarta, Indonesia
}

*Email Korespondensi:

andrian.saputro@undira.ac.id

\section{ARTIKEL INFORMASI}

Diterima:

3 March 2021

Direvisi:

15 April 2021

Dipublikasi: 16 Mei 2021

\begin{abstract}
ABSTRAK
Pada tahun 2014, Cikarang Listrindo Energy membangun PLTU di Babelan untuk berpartisipasi dengan program pemerintah tersebut. Pada tahun 2017 kondisi PLTU Babelan masih dalam tahap commissioning. Pada bulan April 2017 Unit 1 sudah mulai beroperasi. Setelah plant dapat memproduksi listrik selama 3 tahun, maka mulailah dilakukan uji performa untuk setiap komponen utama turbin listrik, salah satunya adalah uji performa turbin uap. Uji performa ini dilakukan untuk mendapatkan hasil dari uji performa secara actual dimana akan dibandingkan dengan data desain awal yang nantinya akan dijadikan standar acuan garansi dari pihak vendor turbin uap tersebut. Uji performa ini dilakukan dengan menggunakan standar dari ASME PTC 6. Uji performa turbin uap dapat dilihat dari beberapa parameter yaitu meliputi Capability test, Heat rate dan efisiensi turbin. Hasil uji performa turbin uap berdasarkan desain yaitu daya output sebesar 138.010 MW, heat rate sebesar $8865 \mathrm{~kJ} / \mathrm{kWh}$, dan efisiensi turbin sebesar $87.38 \%$, sedangkan daya output pada saat commissioning sebesar 139.295 MW, heat rate sebesar $8919 \mathrm{~kJ} / \mathrm{kWh}$, efisiensi turbin sebesar $87.07 \%$, dan daya output pada saat pengambilan data aktual sebesar 137.595 MW, heat rate sebesar $8830.64 \mathrm{~kJ} / \mathrm{kWh}$ dan efisiensi turbin sebesar 88.65 $\%$. Toleransi yang diberikan berdasarkan ASME PTC 6 untuk daya output dan heat rate sebesar $2 \%$. Tekanan exhaust turbin sangat berpengaruh pada peningkatan efisiensi turbin, dimana semakin rendah tekanan exhaust turbin maka efisiensi turbin semakin meningkat.
\end{abstract}

Keyword: Turbin Uap, Performance Test, Capability test, Heat Rate, Efisiensi Turbin

\section{PENDAHULUAN}

Efesiensi dan kehandalan pembangkit tenaga listrik sangat di perlukan selama pengoperasian berlangsung, hal ini berdampak terhadap pemakaian bahan bakar dan ketersediaan cadangan energi primer yang semakin menipis, serta menjaga kehandalan peralatan beroperasi dengan baik. sehingga unit pembangkitan bisa terus beroperasi menjaga sistem kelistrikan yang seefisien mungkin dan melakukan perawatan peralatan yang sangat tepat dan cepat.

PLTU XX merupakan pembangkit listrik yang menggunakan batubara sebagai bahan bakarnya,dengan kapasitas daya sebesar 1x $25 \mathrm{MW}$, sehingga sangat di butuhkan dalam menjaga pasokan listrik pulau Lombok, Pada PLTU Jeranjang Unit 3 ada beberapa parameter pengoperasian yang mengalami penurunan yang 
menyebabkan menurunnya efesiensi pembangkit dan Salah satu tolak ukur efisien tidaknya suatu pembangkit terlihat dari nilai plant heat rate.

Plant heat rate adalah besarnya energi (kJ/kkal) yang dibuthkan untuk membangkitkan satu $\mathrm{kWh}$ electricity. Nilai plant heat rate dipengaruhi oleh nilai turbine heat rate dan efisiensi boiler. Semakin kecil nilai plant heat ratesemakin efisien unit pembangkit tersebut. Perhitungan Plant heat rate juga bertujuan untuk menganalisa suatu system pembangkit terhadap penurunan performance pembangkit tersebut, sehingga dapat memberikan rekomendasi dan membuat langkah-langkah penurunan pada saat perbaikan berkala. dan diharapkan performance pembangkit dapat kembali optimal seperti kondisi saat testing komisioning.

Adapun identifikasi masalah pada penelitian ini adalah Besarnya nilai plant heat rate PLTU aktual sebelum perbaikan berkala, Penyebab kenaikan nilai plant heat rate pada PLTU dan Langkah - langkah untuk menurunkan nilai plant heat rate PLTU dengan demikian nilai plant heat rate dapat mendekati kondisi saat komisioning test.

Tujuan dilakukannya penelitian ini adalaha untuk melakukan analisa terhadap nilai plant heat rate PLTU aktual dibandingkan pada saat komisioning dengan menggunakan metode heat loss. Dari hasil analisa yang diperoleh tersebut diharapkan bisa menjadi rekomendasi pada saat perbaikan. Dengan harapan nilai plant heat rate PLTU setelah perbaikan dapat mendekati kondisi saat komisioning test.

\section{KAJIAN PUSTAKA}

\section{Sistem Pembangkit Listrik Tenaga Uap}

PLTU adalah pembangkit listrik yang mengubah energi kinetik uap menjadi energi listrik. pada PLTU berlangsung melalui 3 tahapan, yaitu :

1) Energi kimia dalam bahan bakar diubah menjadi energi panas dalam bentuk uap bertekanan dan temperatur tinggi.

2) Energi panas (uap) diubah menjadi energi mekanik dalam bentuk putaran.

3) Energi mekanik diubah menjadi energy listrik.

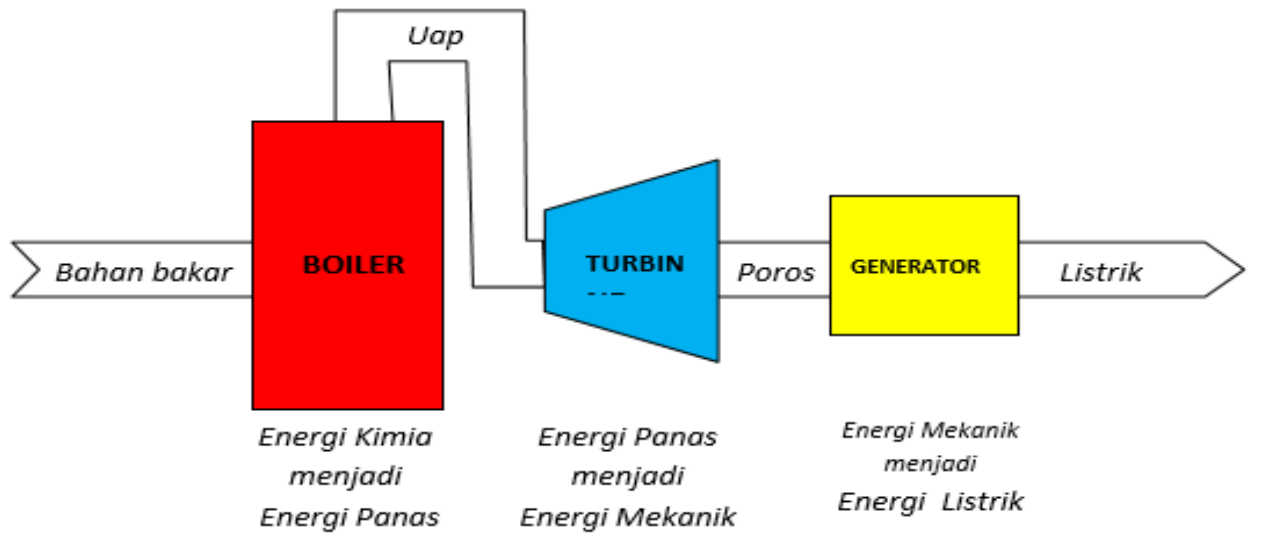

Gambar 1 konversi energi PLTU

Sumber : PLTU Suralaya

\section{Prinsip Kerja Pembangkit Listrik Tenaga Uap}

Siklus rankine banyak digunakan untuk pembangkit termal yang menggunakan uap sebagai media penggerak turbin. Ada 4 peralatan utama pada pembangkit dengan sistem siklus rankine yaitu Boiler, Turbin, Kondensor dan Pompa. 


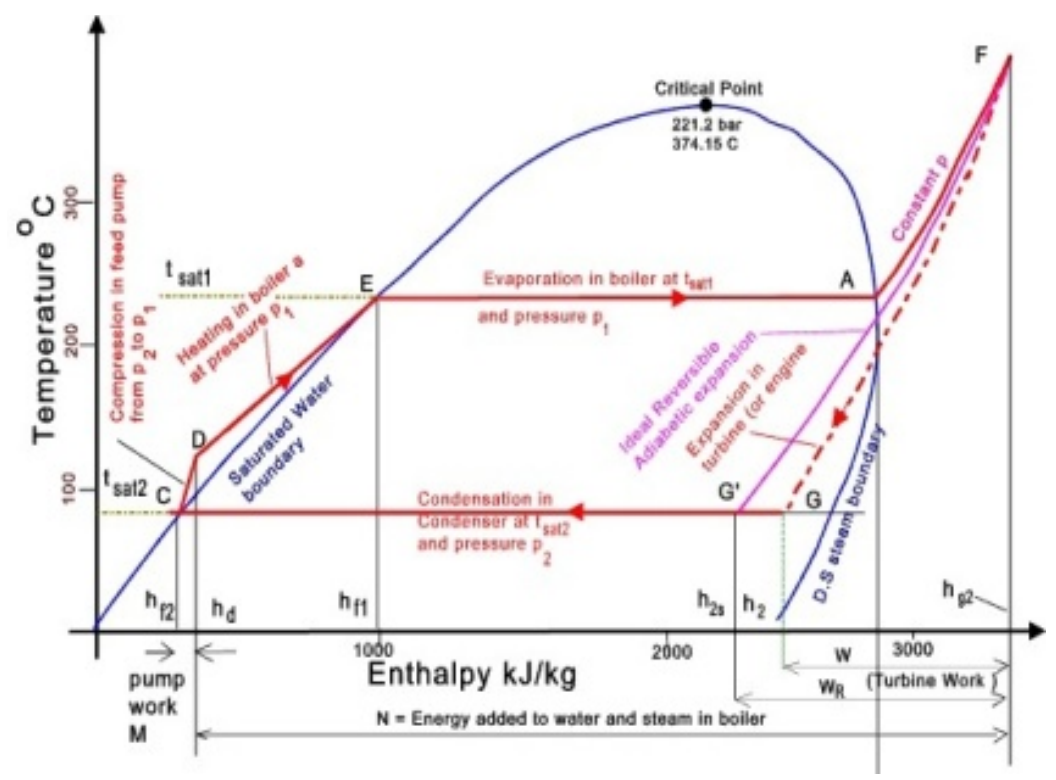

Gambar 2. diagram T-S Siklus Rankine

Sumber : http://artikel-teknologi.com/siklus-rankine/

Pada siklus rankine, air mengalami empat proses sesuai gambar 3 di atas, yaitu:

a) Proses C-D : Proses ini dinamakan proses kompresi-isentropik karena saat dipompa secara ideal tidak ada perubahan entropi yang terjadi.

b) Proses D-F : Air bertekanan tinggi tersebut masuk ke boiler untuk mengalami proses dipanaskan secara isobarik (tekanan konstan).

c) Proses F-G : Proses ini terjadi pada turbin uap. Uap kering dari boiler masuk ke turbin dan mengalami proses ekspansi secara isentropik.

d) Proses G-C : Uap air yang keluar dari turbin uap masuk ke kondensor dan mengalami kondensasi secara isobarik.

\section{Peralatan Utama Pada PLTU}

Peralatan-peralatan utama pada PLTU meliputi :

1) Boiler

Boiler merupakan peralatan yang digunakan untuk merubah energi yang berada pada bahan bakar untuk memproduksi uap panas lanjut yang bertekanan tinggi dan bertemperatur tinggi.

2) Air Heater

Air heater digunakan untuk mema naskan udara pembakaran dengan memanfaatkan laluan gas buang hasil pembakaran pada boiler.

3) Turbin

Turbin uap merupakan suatu komponen pada PLTU yang berfungsi untuk merubah energi termal yang diperoleh dari boiler menjadi energi listrik.

4) Kondensor

Kondensor merupakan perangkat penukar panas untuk mengkondensikan uap keluar turbin hingga berubah fasanya menjadi air kembali. air pendingin kondensor memanfaatkan air laut untuk sirkulasinya.

\section{Plant Heat Rate}

Plant heat rate adalah jumlah energi yang dibutuhkan suatu pembangkit untuk memproduksi $1 \mathrm{kWh}$ energi listrik. Nilai plant heat rate menjadi tolak ukur seberapa efisien unit pembangkit. Ketika nilai plant heat rate lebih rendah maka semakin efisien unit tersebut. Selain itu nilai plant heat rate dapat merefleksikan kondisi suatu unit pembangkit.

\section{Perhitungan Plant Heat Rate Berdasarkan Ptc - 4 \& 6 Metode Energy Balance}

Perhitungan dengan metode ini membutuhkan lebih banyak data sehingga jumlah pengukuran yang dilakukan lebih banyak. Metode energy balance yang digunakan sesuai pada American Society of Mechanichal 
Engineers Performace Test Code (ASME PTC) 4 mengenai fired steam generator dan ASME PTC 6 mengenai steam turbine. Perhitungan plant heat rate metode energy balance dihitung menggunakan rumusan berikut :

$$
\begin{aligned}
& \text { Gross Plant Heat Rate }=\frac{T H R}{\text { Efisiensi Boiler }-100}(\mathrm{~kJ} / \mathrm{kWh} \\
& \text { Net Plant Heat Rate }=\frac{\text { Gross Plant Heat Rate } x \text { Generator Power Output }}{\text { Power Terkirim }}
\end{aligned}
$$

$(\mathrm{kJ} / \mathrm{kWh})$

Dimana :
a. THR : Turbine heat rate $(\mathrm{kJ} / \mathrm{kWh})$
b. Efisiensi boiler dalam satuan persen (\%)
a. Turbine Heat Rate (THR)

Turbine heat rate merupakan energi yang dibutuhkan turbin yang diperoleh dari proses transfer panas untuk menghasilkan $1 \mathrm{kWh}$ electricity.

Turbine Heat Rate $=\frac{\text { Heat in-Heat out }}{\text { Generator Power Output }}$ Persamaan yang digunakan untuk menghitung turbine heat rate sebagai berikut :

Dimana :

$(\mathrm{kJ} / \mathrm{kWh})$

Heat in: Energi panas yang masuk ke turbin $(\mathrm{kJ} / \mathrm{hr})$

Heat out: Energi panas yang keluar dari turbin $(\mathrm{kJ} / \mathrm{hr})$

\section{Heat In}

Heat in merupakan seluruh energi yang masuk pada sistem boundary turbin. Heat in pada turbin merupakan energi pada main steam.

$$
\text { Heat in }=\text { Qms }(\mathrm{kJ} / \mathrm{hr})
$$

$Q m s=M s \times H s(\mathrm{~kJ} / \mathrm{hr})$

Dimana :

Qms : Energi pada main steam $(\mathrm{kJ} / \mathrm{hr})$

Ms : Jumlah aliran main steam $(\mathrm{kg} / \mathrm{hr})$

Hs : Enthalphy pada main steam $(\mathrm{kJ} / \mathrm{kg})$

$\mathrm{Ms}=\mathrm{Mfw}+\operatorname{Mis}(\mathrm{kg} / \mathrm{hr})$

Dimana :

Ms : Jumlah aliran pada main steam $(\mathrm{kg} / \mathrm{hr})$

Mfw : Jumlah aliran pada final feed water $(\mathrm{kg} / \mathrm{hr})$

Mis : Jumlah aliran superheater spraywater $(\mathrm{kg} / \mathrm{hr})$

\section{Heat Out}

Heat out merupakan seluruh energi yang keluar pada sistem boundary turbin. Heat out pada turbin meliputi energi pada final feed water dan superheater spraywater.

Heat out $=Q f w,(\mathrm{~kJ} / \mathrm{hr})$

Heat out $=(M f w H f),(\mathrm{kJ} / \mathrm{hr})$

Dimana :

Mfw $\quad$ :Feed wáter Flow $(\mathrm{kg} / \mathrm{hr})$

Hf: Nilai entalphy $(\mathrm{kg} / \mathrm{hr})$

\section{Efesiensi Boiler}

Efisiensi didefinisikan sebagai perbandingan antara output terhadap input dalam suatu proses.

a. Heat Loss Akibat Dry Gas Losses, dengan persamaan :

Dimana :

$$
Q p L D f g=\frac{H D F g L v C r \times M F r D F g}{H f} 100 \%,(\%)
$$

$\mathrm{HDFgLvCr}$

flue gas excluded leakage $(\mathrm{kJ} / \mathrm{kg})$ $\mathrm{MFrDFg}$
: Enthalphy temperature outlet

: Dry gas $(\mathrm{kg} / \mathrm{kg}-$ fue $)$ 
b. Heat Loss Akibat Kandungan $\mathrm{H}_{2} \mathrm{O}$ Pada Bahan Bakar, dihitung dari :

$$
Q p L W F=\frac{M F r W F \times(H s t L v C r-H W)}{H f} 100 \%,(\%)
$$

Dimana :

MFrWF : Moisture dari pada batubara ( $\mathrm{kg} / \mathrm{kg}-f u e l)$

$\mathrm{Hst} \mathrm{LvCr} \quad$ : Entalphy steam pada AH outlet temperature excluding leakage $(\mathrm{kJ} / \mathrm{kg})$

Hw $\quad:$ Enthalphy of water vapour pada temperatur reference $(\mathrm{kJ} / \mathrm{kg})$

Hf : High heating value batubara $(\mathrm{kJ} / \mathrm{kg})$

c. Heat Loss Akibat Moisture Dari Pembakaran $\mathrm{H}_{2}$

Dimana :

$$
Q p L H 2 F=\frac{M F r W H 2 F x(H s t L v C r-H w)}{H f} 100 \%,(\%)
$$

MFrWH2F : Kandungan moisture dari pembakaran hidrogen $(\mathrm{kg} / \mathrm{kg}-f u e l)$

$H s t L v C r \quad$ : Entalphy steam pada AH outlet temperature exclud ing leakage $(\mathrm{kJ} / \mathrm{kg})$

Hw $\quad:$ Enthalphy of water vapour pada temperatur reference $(\mathrm{kJ} / \mathrm{kg})$

Hf : High heating value batubara $(\mathrm{kJ} / \mathrm{kg})$

d. Heat Losses Akibat Moisture Di Udara dari :

$$
Q p L W A=\frac{M F r W A \times H W v L v C r}{H f} 100 \%,(\%)
$$

Dimana :

MFrWA : $\quad$ Moisture at AH inlet wet air $(\mathrm{kJ} / \mathrm{kg})$

$H W v L v C r \quad:$ Enthalphy water vapor at AH outlet gas exclude leakage $(\mathrm{kJ} / \mathrm{kg})$

Hf : High heating value batubara $(\mathrm{kJ} / \mathrm{kg})$

e. Heat Loss Akibat Unburned Carbon

Dimana :

$$
Q p L U b C=\frac{M p U b C \times 33700}{100 \times H f} 100 \%,(\%)
$$

33700 : Nilai kalor karbon yang terjadi di residu $(\mathrm{kJ} / \mathrm{kg})$

$\mathrm{MpUbC}$ :Karbon yang tidak terbakar saat pembakar an ( $\mathrm{kg} / \mathrm{kg}$-refuse)

Hf $\quad$ :High heating value batubara $(\mathrm{kJ} / \mathrm{kg})$

f. Heat Loss Akibat Surface Radiation Dan Convection

$$
\operatorname{QrLSrC}=\frac{C 1 \times(\mathrm{Hcaz}+\mathrm{Hraz}) \times \mathrm{Afz} \times \mathrm{Tdi}}{3600 \times 1000 \times \mathrm{Hf}} 100 \%,(\%)
$$

\section{Hcaz}

$\operatorname{Hraz}=$

$$
6 T d i^{2}+1.37 E-9 T d i^{3},\left(\mathrm{Btu} / \mathrm{ft}^{2} \mathrm{~h} .{ }^{\circ} \mathrm{F}\right)
$$

Dimana :

Cl : $0.293(\mathrm{~J} / \mathrm{s})$

Hcaz : Koefisien heat transfer konveksi untuk area $z\left(B t u / f t^{2} h .{ }^{\circ} F\right)$

Hraz : Koefisien heat transfer radiasi untuk area $z\left(B t u / f t^{2} h .{ }^{\circ} F\right)$

Afz $\quad$ : Luas permukaan dari casing untuk lokasi $z\left(f t^{2}\right)$

Tdi : Perbedaan temperatur antara temperatur permu kaan casing dengan tempera tur udara ambien di sekitar casing $\left({ }^{p} F\right)$

Hf : High heating value batubara $(\mathrm{kJ} / \mathrm{kg})$

g. Heat Loss Yang Tidak Terukur

$$
\text { QpLUn : Mengacu sesuai design }
$$

h. Heat Losses Akibat Sensible Heat Of Residue

Dimana :

$$
Q p L R s=\frac{(x U c b \times M F r R \times H c b a)+(x U c f \times M F r R \times H c f a)}{H f} 100 \%,(\%)
$$


MFrR : Masa dari residue ( $\mathrm{kg} / \mathrm{kg}-\mathrm{fuel})$

$x U c b \quad:$ Bottom ash split pada desain (\%)

Hcba : Enthalphy bottom ash pada temperatur bottom ash $(\mathrm{kJ} / \mathrm{kg})$

$x U c f$ : Fly ash split pada desain (\%)

Hcfa : Enthalphy fly ash pada temperatur fly ash $(\mathrm{kJ} / \mathrm{kg})$

Hf : High heating value batubara $(\mathrm{kJ} / \mathrm{kg})$

i. Heat Loss Akibat Kandungan Co pada Gas Buang

$$
Q p L C O=\frac{D V p C O \times M O D F g \times M w C O \times H H V C O}{H f} 100 \%,
$$

Dimana :

DVpCO: Kandungan CO pada gas buang (\%)

$\mathrm{MwCO}$ : Berat molekul CO, $28.01(\mathrm{~kg} / \mathrm{mol})$

HHVCO : High heating value CO, $10111(\mathrm{~kJ} / \mathrm{kg})$

MoDFg: mol dari dry gas dengan pengukuran excess air pada lokasi yang sama (moles/kg fuel)

Hf : High heating value batubara $(\mathrm{kJ} / \mathrm{kg})$

j. Heat Loss Akibat Kandungan Nox Pada Gas Buang

Dimana :

$$
\begin{gathered}
\text { QpLNOx =DvpNOx MoDFg } \frac{\text { HrNOx }}{H f} 100 \%,(\%) \\
M o D F g=\text { MoDPc MoThACr }\left(0.7905+\frac{X p A}{100}\right),(\text { mol/fuel })
\end{gathered}
$$

DvpNOx: Jumlah NOx pada volume gas buang (\%)

MoDFg : mol dari dry gas dengan pengukuran excess air pada lokasi yang sama (moles/kg fuel)

HrNOx : Formasi panas dari $\mathrm{NO}=89950(\mathrm{~kJ} / \mathrm{gm} \mathrm{mol})$

Hf : High heating value batubara $(\mathrm{kJ} / \mathrm{kg})$

6. Heat Credit

a. Credit Pada Udara Masuk

$$
Q p B D A=\frac{M F r D A \times H D A}{H f} 100 \%,(\%)
$$

Dimana :

MFrDA : Jumlah udara yang masuk ke boiler $(\mathrm{kg} / \mathrm{kg}$-fuel)

HDA : Enthalpy of dry air at AH inlet air $(\mathrm{kJ} / \mathrm{kg})$

Hf : High heating value batubara $(\mathrm{kJ} / \mathrm{kg})$

b. Credit Pada Moisture Di Udara Masuk

$$
Q p B W A=\frac{M F r W A \times H W v}{H f} 100 \%,(\%)
$$

Dimana :

MFrWA : Moisture at AH inlet wet air $(\mathrm{kJ} / \mathrm{kg})$

$H W v \quad$ : Enthalpy of dry vapor at AH inlet air $(\mathrm{kJ} / \mathrm{kg})$

Hf $\quad$ :High heating value batubara $(\mathrm{kJ} / \mathrm{kg})$

c. Credit Sensible Heat Pada Bahan Bakar

$$
Q p B F=\frac{H d b}{H f} 100 \%,(\%)
$$

Dimana :

$H d b$ : Enthalphy dari dry air fuel temperatur masuk boiler $(\mathrm{kJ} / \mathrm{kg})$

Hf : High heating value batubara $(\mathrm{kJ} / \mathrm{kg})$

Dalam perhitungan efisiensi boiler dengan metode heat loses, energi input dapat dituliskan sebagai :

$$
E F=100-S m Q p L+S m Q p B,
$$

$S m Q p l=Q p L D F g+Q p L W F+Q p L H 2 F+Q p L W A+Q p L U b C+Q r L S r c+Q p L U n+Q p L R s$

$S m Q p B=Q p B D A+Q p B W A+Q p B F,(\%)$

Dimana :

SmQpL : Jumlah losses yang terhitung berdasarkan input bahan bakar (\%)

$S m Q p B \quad$ : Jumlah credit yang terhitung bedasarkan input bahan bakar (\%) 


\section{METODE}

Metodologi penelitian merupakan tahap-tahap penelitian yang harus ditetapkan dahulu sebelum melakukan pemecahan masalah, sehingga penelitian dapat dilakukan dengan terarah dan memudahkan dalam menganalisis permasalahan yang ada. Berikut diagram alir Metode Penelitian yang digunakan dapat dilihat pada gambar 3 berikut :

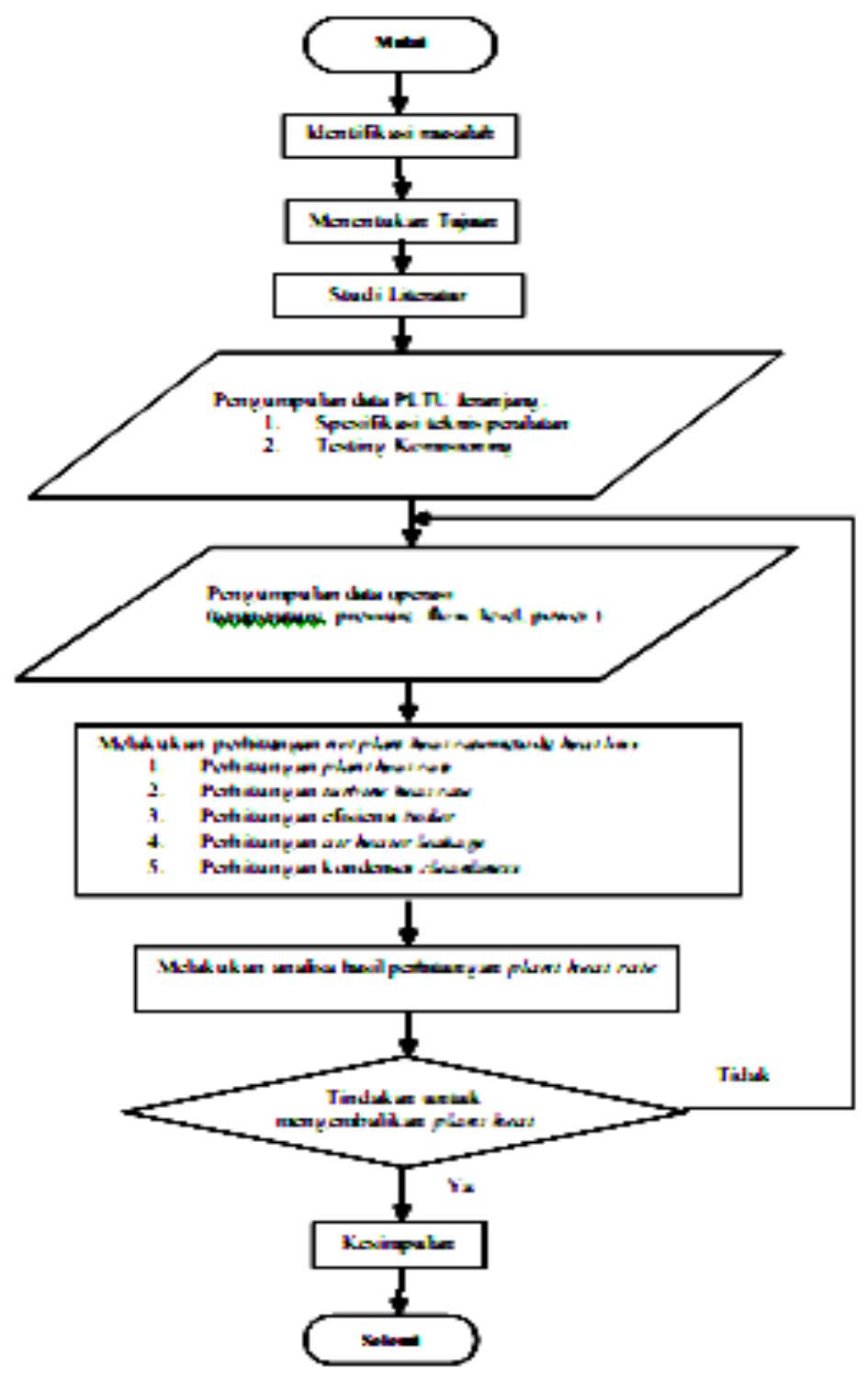

Gambar 3. Diagram alir proses penelitian.

\section{Prosedur Pengambilan Data}

Pengukuran parameter-parameter yang dibutuhkan adalah dengan mengambil data dari desain awal turbin uap. Data ini digunakan sebagai data pembanding untuk pengujian performa turbin uap secara aktual. Setelah data desain diolah menggunakan persamaan yang telah dibahas pada bab sebelumnya, selanjutnya adalah mengambil beberapa parameter yang akan digunakan untuk pengolahan data.Data diambil setiap 1 minggu selama 4 jam sekali yaitu pada bulan Mei minggu ketiga 2020 sampai dengan Agustus 2020 sesuai dengan minimum pengambilan data dari ASME PTC 6. Selain itu pengambilan data dilakukan pada saat sistim dalam keadaan base load.

Base load merupakan kondisi dimana turbin uap secara maksimal menghasilkan daya output berupa daya listrik. Hal tersebut dilakukan agar hasil pengolahan data mempunyai nilai pada saat kondisi yang sama sehingga hasilnya tidak rancu. 


\section{Spesifikasi Data Dan Perhitungan}

Data yang di jelaskan pada Bab ini ialah data hasil dari komisioning PLTU Babelan, Bekasi, dan data actual berdasarkan hasil pemantauan dan pengukuran.

\section{Heat Rate}

Dengan mengambil salah satu sampel penelitian, maka dilakukan perhitungan sebagai berikut :

$$
\begin{aligned}
& \mathrm{m}_{\text {in }} \quad=134 \mathrm{~kg} / \mathrm{s} \\
& \mathrm{h}_{\text {in }} \quad=3450.5 \mathrm{~kJ} / \mathrm{s} \\
& \mathrm{m}_{\mathrm{fw}} \quad=130.304 \mathrm{~kg} / \mathrm{s} \\
& \mathrm{h}_{\mathrm{fw}} \quad=924.4 \mathrm{~kJ} / \mathrm{s} \\
& \mathrm{m}_{\text {blow }} \quad=0.33 \mathrm{~kg} / \mathrm{s} \\
& \text { h } \quad=2662.9 \mathrm{~kJ} / \mathrm{s} \\
& \mathrm{m}_{\text {desu }} \quad=4.021 \mathrm{~kg} / \mathrm{s} \\
& \mathrm{h}_{\text {desu }} \quad=722.3 \mathrm{~kJ} / \mathrm{s}
\end{aligned}
$$

\begin{tabular}{|c|c|}
\hline $\mathrm{m}_{\text {in }}$ & $=134 \mathrm{~kg} / \mathrm{s}$ \\
\hline $\mathrm{T}_{\text {in }}$ & $=540{ }^{\circ} \mathrm{C}$ \\
\hline$P_{\text {in }}$ & $=125 \mathrm{Bar}$ \\
\hline $\mathrm{h}_{\text {in }}$ & $=3450.5 \mathrm{~kJ} / \mathrm{kg}$ \\
\hline$m_{\text {eks1 }}$ & $=6.14 \mathrm{~kg} / \mathrm{s}$ \\
\hline $\mathrm{T}_{\mathrm{eks} 1}$ & $=303.5^{\circ} \mathrm{C}$ \\
\hline$P_{\text {eks1 }}$ & $=22.41 \mathrm{Bar}$ \\
\hline$h_{\text {eks1 }}$ & $=3025.4 \mathrm{~kJ} / \mathrm{kg}$ \\
\hline $\mathrm{m}_{\mathrm{eks} 2}$ & $=5.61 \mathrm{~kg} / \mathrm{s}$ \\
\hline $\mathrm{T}_{\text {eks2 }}$ & $=249.9^{\circ} \mathrm{C}$ \\
\hline $\mathrm{P}_{\mathrm{eks} 2}$ & $=13.95 \mathrm{Bar}$ \\
\hline$h_{\text {eks2 }}$ & $=2927.83 \mathrm{~kJ} / \mathrm{kg}$ \\
\hline $\mathrm{m}_{\text {eks3 }}$ & $=8.32 \mathrm{~kg} / \mathrm{s}$ \\
\hline $\mathrm{T}_{\text {eks3 }}$ & $=183.8^{\circ} \mathrm{C}$ \\
\hline $\mathrm{P}_{\mathrm{eks} 3}$ & $=7.41 \mathrm{Bar}$ \\
\hline$h_{\text {eks3 }}$ & $=2805.6 \mathrm{~kJ} / \mathrm{kg}$ \\
\hline $\mathrm{m}_{\text {eks } 4}$ & $=8.7 \mathrm{~kg} / \mathrm{s}$ \\
\hline $\mathrm{T}_{\text {eks4 }}$ & $=134^{\circ} \mathrm{C}$ \\
\hline $\mathrm{P}_{\mathrm{eks} 4}$ & $=3.04 \mathrm{Bar}$ \\
\hline $\mathrm{h}_{\mathrm{eks} 4}$ & $=2725.55 \mathrm{~kJ} / \mathrm{kg}$ \\
\hline $\mathrm{m}_{\text {eks } 5}$ & $=6.93 \mathrm{~kg} / \mathrm{s}$ \\
\hline $\mathrm{T}_{\text {eks } 5}$ & $=92.6^{\circ} \mathrm{C}$ \\
\hline$P_{\text {eks } 5}$ & $=0.77 \mathrm{Bar}$ \\
\hline $\mathrm{h}_{\mathrm{eks} 5}$ & $=2663.81 \mathrm{Kj} / \mathrm{kg}$ \\
\hline$P_{\text {out }}$ & $=0.15 \mathrm{Bar}$ \\
\hline $\mathrm{T}_{\text {out }}$ & $=54.5^{\circ} \mathrm{C}$ \\
\hline$h_{\text {out }}$ & $=2382.5164 \mathrm{~kJ} / \mathrm{kg}$ \\
\hline
\end{tabular}

$H R=\frac{Q}{\text { Pgenerator }} \times 3600$

$Q=(\min$. hin $)-($ mfw. hfw $)+($ mblow. hblow $)-($ mdesu. hdesu $)$

$$
H R=\frac{(134 \times 3450.5)-(130.304 \times 924.4)+(0.33 \times 2662.9)-(4.021 \times 722.3)}{138000} \times 3600=8865 \frac{\mathrm{kJ}}{\mathrm{kWh}}
$$

\section{Turbine Efficiency}

Untuk mendapatkan nilai dari entalphy isentropis yaitu dengan cara memplot data pada diagram mollier atau menggunakan steam table. Pada diagram mollier atau steam table dapat dicari dengan cara memplot nilai dari kuliatas uap (x) dengan tekanan exhaust $\left(\mathrm{P}_{\text {out }}\right)$

$\mathrm{X}=0.83$, Hisent $=2194.99 \mathrm{~kJ} / \mathrm{kg}$

$T \eta=\frac{\text { WTtotal actual }}{\text { WTtotal Isentropis }} \times 100 \%$ 
WTeks $1=\min ($ hin - heks 1$)$

WTeks $2=(\min -\operatorname{meks} 1) .($ heks $1-$ heks 2$)$

WTeks $3=(\min -$ meks $1-$ meks 2$) .($ heks $2-$ heks 3$)$

WTeks $4=(\min -$ meks $1-$ meks $2-$ meks 3$) .($ heks $3-$ heks 4$)$

WTeks $5=(\min -$ meks $1-$ meks $2-$ meks $3-$ meks 4$) .($ heks $4-$ heks 5$)$

WTeks $6=(\min -$ meks $1-$ meks $2-$ meks $3-$ meks $4-$ meks 5$) .($ heks $5-$ hout $)$

WTisent $=(\min -$ meks $1-$ meks $2-$ meks $3-$ meks $4-$ meks 5$) .($ heks $5-$ hisent $)$

WTeks $1=134 .(3450.5-3025.4)=56963.4 \mathrm{~kW}$

WTeks $2=(134-6.14) .(3025.4-2927.83)=12475.3 \mathrm{~kW}$

WTeks $3=(134-6.14-5.61) .(2927.83-2805.6)=14942.62 \mathrm{~kW}$

WTeks $4=(134-6.14-5.61-8.32) .(2805.6-2725.55)=9210.1 \mathrm{~kW}$

WTeks $5=(134-6.14-5.61-8.32-8.7) .(2725.55-2663.81)=6496.9 \mathrm{~kW}$

WTeks $6=(134-6.14-5.61-8.32-8.7-6.93) .(2663.81-2382.516)=27651.16 \mathrm{~kW}$

Wisent $=(134-6.14-5.61-8.32-8.7-6.93) .(2663.81-2194.99)=46085.006 \mathrm{~kW}$

Mencari daya total turbin uap aktual

WTtotal aktual $=$ WTeks $1+$ WTeks $2+$ WTeks $3+$ WTeks $4+$ WTeks $5+$ WTeks 6

WTtotal aktual $=56963.4+12475.3+14942.62+9120.1+6496.9+27651.16$

WTtotal aktual $=127649.48 \mathrm{~kW}$

Mencari daya total turbin uap isentropis

WTtotal isent $=$ WTeks $1+$ WTeks $2+$ WTeks $3+$ WTeks $4+$ WTeks $5+$ Wisent

WTtotal isent $=56963.4+12475.3+14942.62+9120.1+6496.9+46085.006$

WTtotal isentropis $=146083.326 \mathrm{~kW}$

$T \eta=\frac{\text { WTtotal actual }}{\text { WTtotal Isentropis }} \times 100 \%$

$T \eta=\frac{127649.48}{146083.326} \times 100 \%=87.38 \%$

\section{HASIL DAN PEMBAHASAN}

Perbandingan Daya Output Desain, Daya Output Commissioning dan Daya Output Aktual

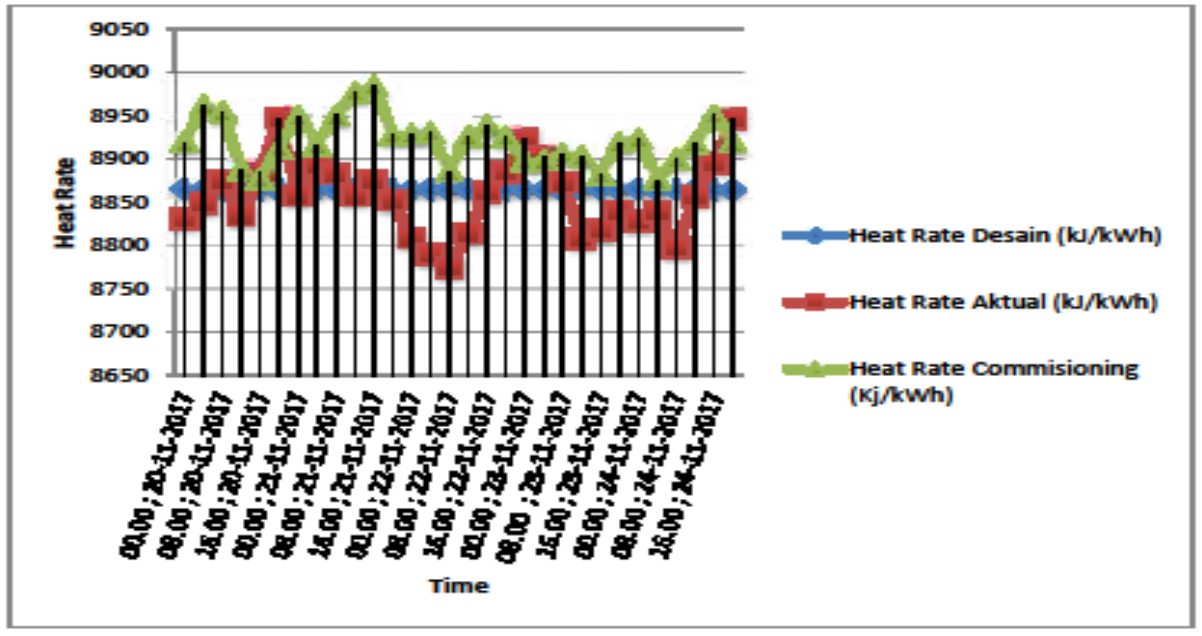

Gambar 4. Grafik Perbandingan Daya Output

Dari gambar 4. dapat dilihat bahwa daya output pada saat commissioning lebih besar dibandingkan dengan daya output secara desain maupun pada saat aktual pengambilan data. Daya output desain sebesar 
138.010 MW, sedangkan daya output pada saat commissioning yaitu 139.295 MW atau mempunyai deviasi sekitar $0.9 \%$ lebih besar dibandingkan data desain, dan daya output pada saat pengambilan data aktual sebesar 137.595 MW atau mempunyai deviasi $0.3 \%$ lebih kecil dibandingkan dengan desain . Untuk toleransi daya output yang diberikan berdasarkan ASME PTC 6 yaitu sebesar 2\%. Jadi untuk daya output pada saat commissioning maupun pada saat pengambilan data aktual masih dalam range toleransi yang diberikan. Daya output pada saat commissioning lebih besar dikarenakan pada saat performance test commissioning energi uap yang masuk lebih besar dibandingkan dengan data desain maupun pada saat pengambilan data aktual.

\section{Perbandingan Heat Rate Desain,Heat Rate Aktual, dan Heat Rate Commisioning}

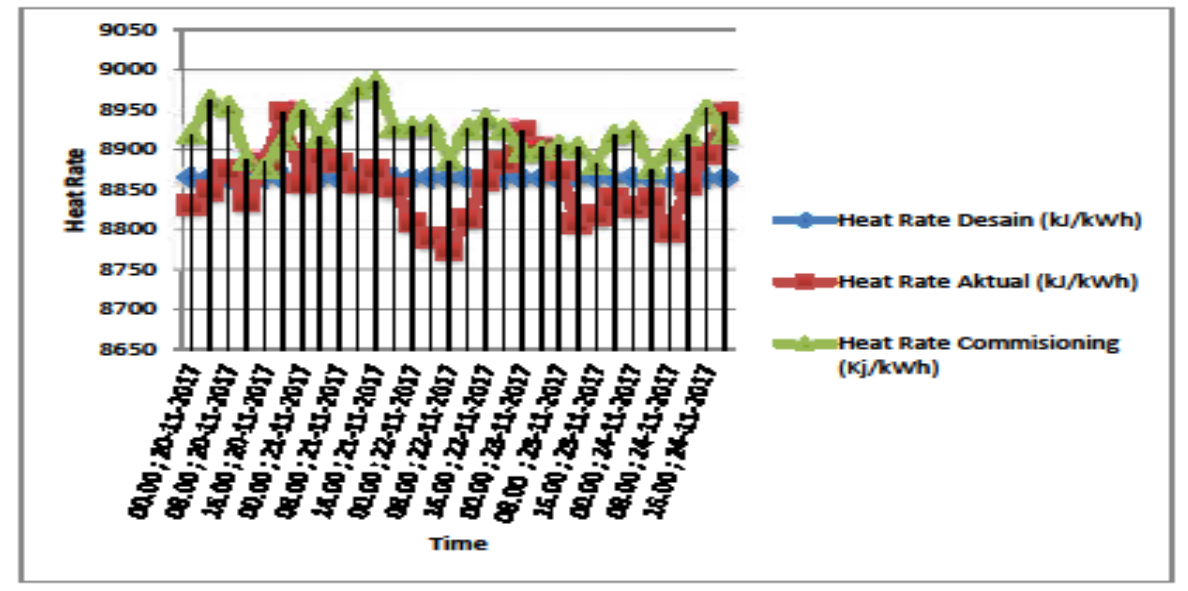

Gambar 5. Grafik Perbandingan Heat Rate

Dari gambar 5 dapat dilihat bahwa heat rate pada saat commisoning cenderung lebih besar dibandingkan dengan heat rate desain maupun heat rate pada saat pengambilan data aktual. Heat rate desain yaitu sebesar $8865 \mathrm{~kJ} / \mathrm{kWh}$ sedangkan heat rate commisioning sebesar $8919 \mathrm{~kJ} / \mathrm{kWh}$ atau mempunyai deviasi sebesar $0.9 \%$ lebih besar dibandingkan heat rate desain, dan untuk heat rate pada saat pengambilan data aktual sebesar 8830 $\mathrm{kJ} / \mathrm{kWh}$ atau mempunyai deviasi sebesar $0.39 \%$ lebih kecil dari heat rate desain. Untuk toleransi dari heat rate sendiri berdasarkan ASME PTC 6 yaitu sebesar 2\% . Jadi untuk heat rate pada saat commissioning maupun pada saat pengambilan data aktual masih masuk dalam range toleransi yang diberikan. Semakin besar nilai heat rate maka nilai efisiensi turbin akan turun, hal ini menyebabkan konsumsi bahan bakar untuk memanaskan air menjadi uap semakin bertambah.

\section{Perbandingan Turbine Efficiency Desain,TurbineEfficiency Commissioning, Turbin Effeciency Aktual}

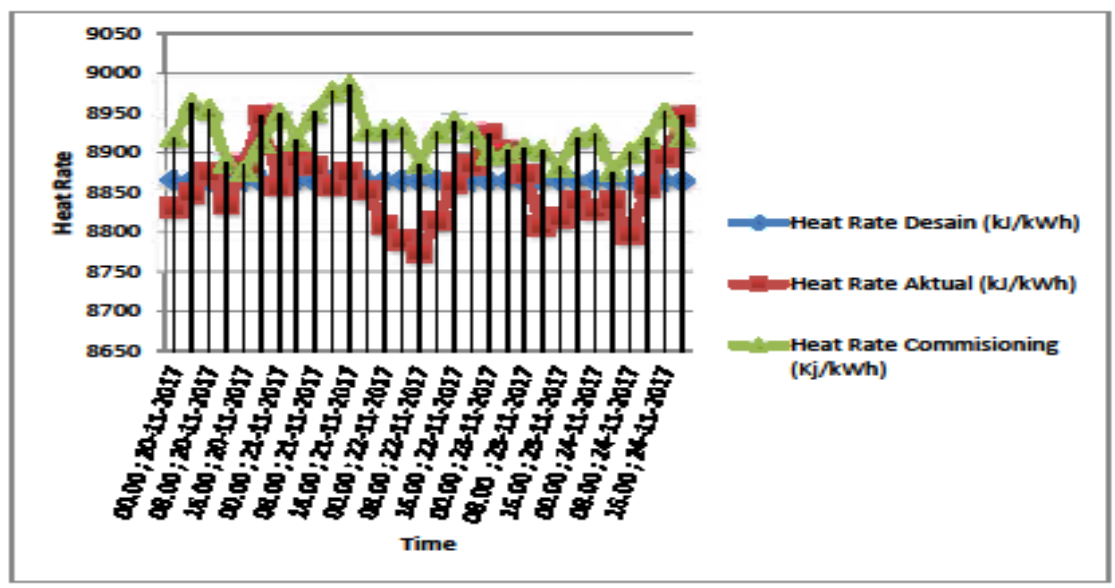

Gambar 6 Grafik Perbandingan Efisiensi Turbin

Dari gambar 6 dapat dilihat bahwa efisiensi turbin aktual lebih besar dibandingkan dengan efisiensi turbin pada saat commissioning maupun efisiensi turbin desain. Nilai efisiensi turbin aktual sebesar $88.21 \%$, sedangkan efisiensi turbin pada saat commisoning yaitu sebesar $87.1 \%$ dan efisiensi turbin desain sebesar 
87.38\%. Efisiensi turbin aktual lebih besar karena exhaust pressure pada saat pengambilan data aktual lebih vacuum dibandingkan dengan data desain maupun pada saat commissioning. Besarnya efisiensi turbin ditentukan berdasarkan seberapa vacuum exhaust pressure dari turbin uap tersebut. Bisa kita lihat dari data yang didapatkan bahwa exhaust pressure desain sebesar 0.15 Bar,sedangkan exhaust pressure pada saat commissioning sebesar 0.15 Bar dan exhaust pressure data aktual sebesar 0.126 Bar.

\section{KESIMPLAN DAN SARAN}

Dari analisis dan perhitungan yang telah dilakukan pada turbin uap jenis condensing extraction turbine , maka dapat disimpulkan bahwa :

1) Daya output desain sebesar $138.010 \mathrm{MW}$, sedangkan daya output pada saat commissioning sebesar 139.295 MW, dan daya output aktual sebesar 137.595 MW. Toleransi dari daya output berdasarkan ASME PTC 6 sebesar $2 \%$ dari data desain, sehingga untuk daya output commissioning maupun daya output aktual masih masuk dalam toleransi yang diberikan.

2) Heat rate turbin desain sebesar $8865 \mathrm{~kJ} / \mathrm{kWh}$, sedangkan heat rate turbin pada saat commissioning sebesar $8919 \mathrm{~kJ} / \mathrm{kWh}$, dan heat rate turbin aktual sebesar $8831 \mathrm{~kJ} / \mathrm{kWh}$. Toleransi yang diberikan berdasarkan ASME PTC 6 sebesar 2\%, sehingga untuk heat rate turbin pada saat commissioning dan pada saat pengambilan data aktual masih masuk dalam range yang diberikan.

3) Efisiensi turbin desain sebesar $87.38 \%$, sedangkan efisiensi turbin pada saat $87.068 \%$ dan efisiensi turbin pada saat pengambilan data aktual sebesar $88.65 \%$. Efisiensi turbin sangat dipengaruhi oleh kevakuman dari exhaust turbin sendiri

4) Dari hasil penelitian performa turbin uap pada saat commissioning maupun pada saat pengambilan data aktual, semua parameter-paramater yang diuji masih masuk dalam toleransi yang diberikan berdasarkan dari ASME PTC 6

5) Steam flow dan energi uap yang masuk mempengaruhi besarnya efisiensi turbin, hal ini dapat kita lihat dimana energi uap pada saat pengambilan data aktual lebih besar yaitu sebesar $3463.4 \mathrm{~kJ} / \mathrm{kg}$ dengan efisiensi sebesar $88.65 \%$, sedangkan energi uap pada data desain sebesar $3450 \mathrm{~kJ} / \mathrm{kg}$ dengan efisiensi sebesar 87.38\%dan energi uap pada saat commissioning sebesar $3445.73 \mathrm{~kJ} / \mathrm{kg}$ dengan efisiensi sebesar 87.1\%. Menjaga kevakuman dari exhaust turbin atau kevakuman dari Air Cooled Condensor sangat berpengaruh pada peningkatan efisiensi turbin

6) Salah satu penyebab turunnya efisiensi turbin ialah naiknya pressure pada air cooled condenser, hal ini bisa kita lihat pada grafik perbandingan antara efisiensi turbin desain,commissioning dan aktual, dimana semakin vacuum pressure exhaust turbin atau pressure air cooled condenser, maka efisiensi turbin akan semakin turun. Salah satu cara untuk menjaga kevakuman pada air cooled condenser agar exhaust pressure turbin rendah dibutuhkan penjadwalan proses pembersihan tube-tube pada air cooled condenser agar terhindar dari penumpukan kotoran pada tube-tube air cooled condenser, dimana akan berpengaruh pada proses kondensasi uap keluaran turbin, hal ini termasuk upaya dalam menjaga kevakuman exhaust turbine dan dapat meningkatkan efisiensi dari turbin itu sendiri.

\section{REFERENCES}

American Society of Mechanichal Engineering. 2008. Performance Test Code 4. New York : HIS

American Society of Mechanichal Engineering. 2008. Performance Test Codes 6. New York : HIS

Power Plant Enginering Black And Veatch, 2008

Daffiqurrohman, Hafif. (2013). Laporan Kerja Praktik Machinery and Heavy Equipment Division. PT Badak LNG.

Permana,Dedi . (2012). Materi Presentasi Steam Turbine LNG Academy. Bontang: PT Badak.

Moran, Michel. J, Shapiro, Howard N. 2006. Fundamental of Enginering Thermodynamics (Fifth Edition). England: John Wiley and Sons.

American Society of Mechanical Engineer. 2006. Erratum to ASME PTC 6-2004 Steam Turbine. New York, USA: ASME.

Siemens.(2014). Operation and Maintenance Manual Book Steam Turbine. Germany. 